Check for updates

Cite this: RSC Adv., 2017, 7, 55051

\title{
Ligand steric effects on $\alpha$-diimine nickel catalyzed ethylene and 1-hexene polymerization $\uparrow$
}

\begin{abstract}
Jinlong Sun, ${ }^{a}$ Fuzhou Wang, (D)*ab Weimin $\mathrm{Li}^{\mathrm{a}}$ and Min Chen ${ }^{\star a}$
A series of ortho-dibenzhydryl or ortho-sec-phenethyl substituted $\alpha$-diimine nickel complexes with systematically varied ligand steric effects were used as precatalysts for the polymerization of ethylene and 1-hexene upon activation with $\mathrm{Et}_{2} \mathrm{AlCl}$. The effects of ligand sterics and polymerization temperature on the catalytic activity, molecular weight and polymer microstructure were evaluated in detail. In ethylene polymerization, it is possible to tune the catalytic activities $\left[(0.98-2.41) \times 10^{6} \mathrm{~g}(\mathrm{~mol} \mathrm{Ni} \mathrm{h})^{-1}\right]$, polymer molecular weights $\left[M_{\mathrm{n}}:(1.8-13.1) \times 10^{5} \mathrm{~g} \mathrm{~mol}^{-1}\right]$ and branching densities (55-108/1000C) over a very wide range. The molecular weights and branching structure depended on the nickel complexes as well as the polymerization temperature, and the polymer branching densities were decreased with increasing ligand steric effects and decreasing polymerization temperature. Polymerization of 1-hexene with ortho-dibenzhydryl substituted nickel complexes resulted in branched polymers (106-140/1000C) with high molecular weights $\left[M_{\mathrm{n}}:(0.64-3.88) \times 10^{4} \mathrm{~g} \mathrm{~mol}^{-1}\right]$ and narrow molecular weight distribution $\left(M_{w} / M_{n}=1.16-1.52,40-80^{\circ} \mathrm{C}\right)$. The increasing steric hindrance of the catalyst leads to enhanced 2,1insertion of 1-hexene and the chain-walking reaction.
\end{abstract}

Received 25th October 2017 Accepted 28th November 2017

DOI: $10.1039 / c 7 r a 11783 c$

rsc.li/rsc-advances a long methylene sequence in a $\omega, 1$-enchainment (iv). If the metal fails to chain walk after 1,2-insertion, the final polymer contains $n$-alkyl branches (ii), which is found in common poly( $\alpha$-olefin)s. The highly-branched polymers with high amounts of methyl and alkyl branches are amorphous, while the chain-straightened polymers will be semi-crystalline. ${ }^{6}$

Previous studies indicated that sterically bulky ligands are usually required to afford nickel and palladium catalysts capable of generating high molecular weight polymers. ${ }^{2 c}$ Chain straightening polymerization of $\alpha$-olefins can generate highly linear polyethylene, which is the most abundantly produced plastic owing to its inexpensive monomer, thermoplastic properties, and semi-crystalline nature. ${ }^{4 d, 8}$ The branching degree of the polymer can be controlled via catalyst structures (Chart 1) and polymerization conditions such as ethylene pressures or polymerization temperatures., ${ }^{\mathbf{9} 10}$ For example, $\mathrm{Wu}$ et al. synthesized a camphyl-based $\alpha$-diimine nickel catalyst $\mathbf{C 1}$ that can polymerize ethylene, propylene and $\alpha$-olefins in a living fashion under the optimized conditions. ${ }^{\mathbf{1 1}}$ This catalyst exhibited 1,3-enchainment fraction of $45 \%$ in propylene polymerization, and produced poly( $\alpha$-olefin)s with an obvious $T_{\mathrm{m}}$. Brookhart et al. reported a "sandwich" (8- $p$-tolyl naphthyl) substituted $\alpha$-diimine nickel catalyst $\mathbf{C 2}$ that yielded highlybranched (up to 152 branches/1000C) polyethylene. ${ }^{12}$ Coates et al. reported that the living/controlled polymerization of propylene and higher $\alpha$-olefins using $C_{2}$-symmetric $\alpha$-diimine nickel catalyst C3a bearing chiral sec-phenethyl moiety. ${ }^{13}$ Recently, the same group synthesized a dibenzobarrelenebridged $\alpha$-diimine nickel catalyst $\mathbf{C 3 b}$ bearing chiral sec-
School of Petrochemical Engineering, Changzhou University, Changzhou 213164, China.E-mail: wangfuzhou1718@126.com; misschen@ustc.edu.cn

${ }^{b}$ Graduate School of Engineering, Hiroshima University, Kagamiyama 1-4-1, HigashiHiroshima 739-8527, Japan

$\dagger$ Electronic supplementary information (ESI) available: NMR spectra of ligands and polymers; GPC curves of polymers. CCDC 1576125, 1576349, 1468457 contain the supplementary X-ray crystallographic data for complexes 2, 3 and 5 For ESI and crystallographic data in CIF or other electronic format see DOI: $10.1039 / \mathrm{c} 7 \mathrm{ra} 11783 \mathrm{c}$ 


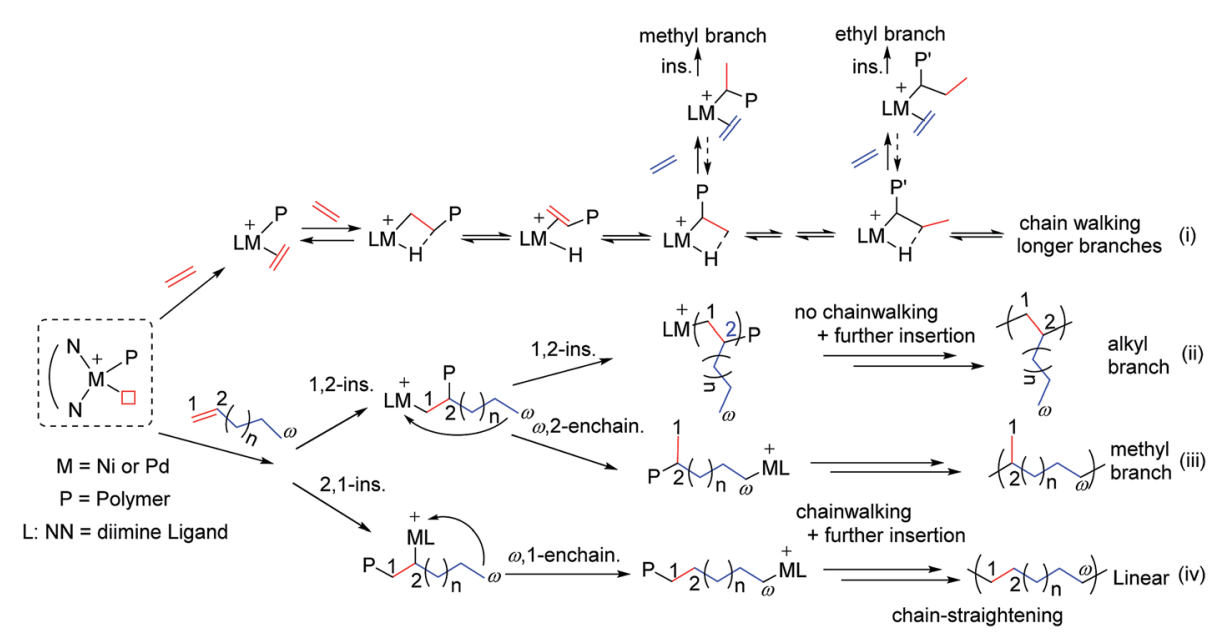

Scheme 1 Chain-walking mechanism for ethylene and $\alpha$-olefin polymerization catalyzed by $\alpha$-diimine nickel and palladium complexes.

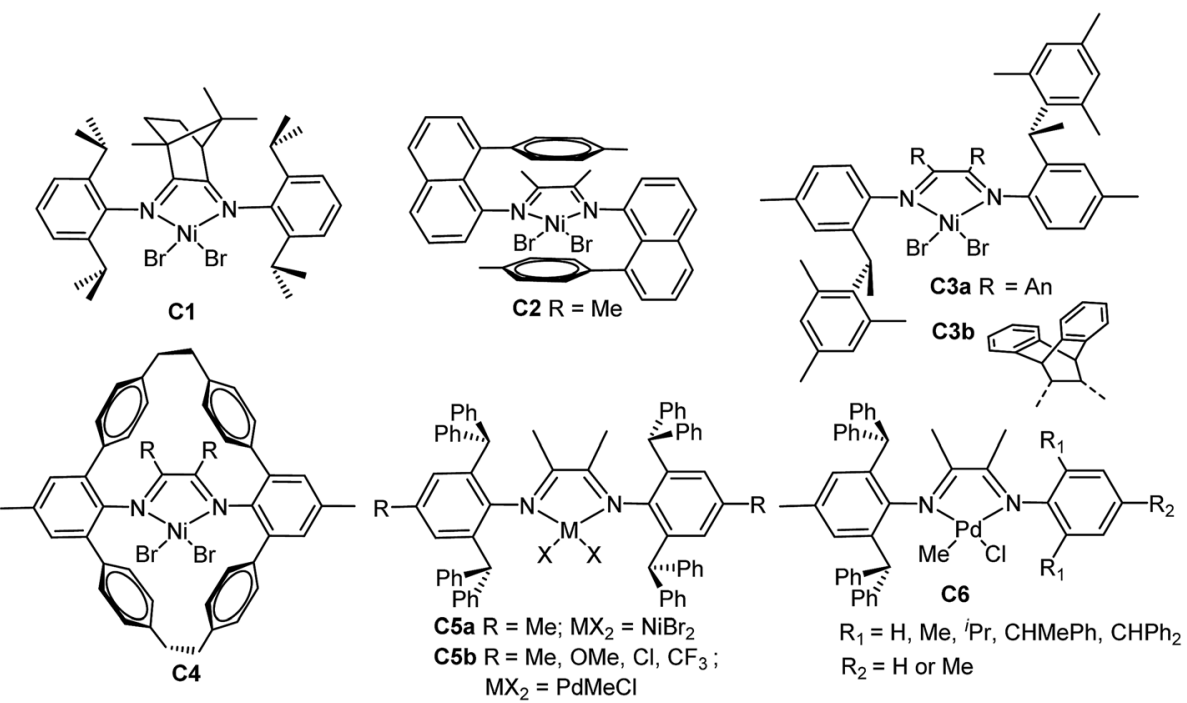

Chart 1 Selected examples of $\alpha$-diimine nickel and palladium catalysts.

phenethyl moiety. ${ }^{4 d}$ The catalyst afforded high molecular weight polyethylenes with narrow dispersities and low degrees of branching, and demonstrated living behavior at room temperature and produced linear polyethylene $\left(T_{\mathrm{m}}=135^{\circ} \mathrm{C}\right)$ at $-20^{\circ} \mathrm{C}$. Guan et al. designed a $\alpha$-diimine nickel catalyst $\mathbf{C 4}$ bearing a macrocyclic ligand, which showed significantly higher thermal stability than the acyclic analogs, and promoted living polymerization of propylene even at $50-75{ }^{\circ} \mathrm{C} .{ }^{14}$ This type of catalyst enhances both the 2,1-insertion of propylene and the chain-walking reaction. Long et al. examined $\alpha$-diimine nickel catalysts C5a containing ortho-dibenzhydryl moiety for hightemperature ethylene polymerization,${ }^{15}$ where the catalyst maintained high activities at temperatures as high as $100^{\circ} \mathrm{C}$.

Chen et al. recently reported that $\alpha$-diimine palladium catalysts C5b bearing the dibenzhydryl moiety displayed high thermal stability and high activity in slow chain-walking ethylene (co)polymerization, ${ }^{16}$ producing semicrystalline polyethylene and ethylene/methyl acrylate copolymer with high molecular weight and low branching density. They also designed a series of $\alpha$-diimine palladium catalysts $\mathbf{C 6}$ bearing both the dibenzhydryl moiety and with systematically varied ligand sterics for ethylene and 1-hexene polymerization, ${ }^{17}$ the molecular weights and branching densities could be tuned over a very wide range. In this work, we wish to report the synthesis of a series of ortho-dibenzhydryl and ortho-sec-phenethyl substituted $\alpha$-diimine nickel complexes with systematically varied ligand sterics, and the investigation of the influence of ligand structure and polymerization conditions on ethylene and 1-hexene polymerizations.

\section{Results and discussion}

\section{Synthesis and characterization of the nickel complexes}

The desired ligands were prepared using the literature procedure in high yields without using column chromatography. ${ }^{17,18}$ $\alpha$-Diimine nickel precatalysts used in this study are summarized 

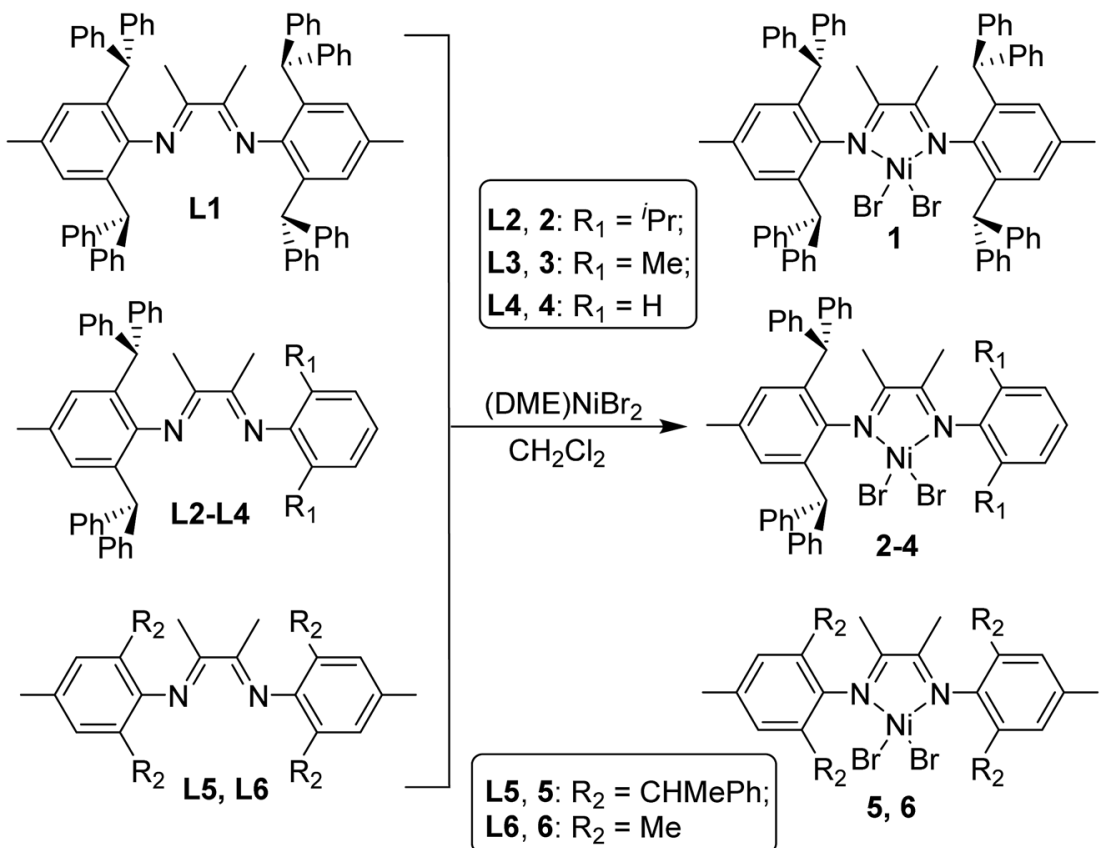

Scheme 2 Synthesis of $\alpha$-diimine nickel complexes $1-6$.

in Scheme 2. Complexes 2-4 were synthesized from the reactions of the corresponding ligand with (DME) $\mathrm{NiBr}_{2}$ in high yields. Chen et al. previously reported ortho-dibenzhydryl and ortho-sec-phenethyl substituted nickel complexes $1^{4 f}$ and $5^{18}$ that exhibited high activities in ethylene polymerization and produced different branched polyethylene with high molecular weight. Complexes $\mathbf{1}$ and $\mathbf{5}$ were prepared and studied in order to obtain accurate comparisons in ethylene polymerization. This way, a series of $\alpha$-diimine nickel complexes bearing orthodibenzhydryl and ortho-sec-phenethyl groups and with systematically varied ligand sterics could be studied in the polymerization of ethylene and 1-hexene. In addition, the methyl substituted complex 6 was also used for comparison in this study.

\section{X-ray crystallographic studies}

Suitable crystals of complexes 2,3 and 5 were obtained by layering $n$-hexane onto their dichloromethane solution at room temperature, respectively. The molecular structures of 2,3 and 5 was confirmed by single-crystal X-ray diffraction and the corresponding ORTEP diagram with selected bond distances and angles are shown in Fig. 1, 2 and 3, respectively. Crystal data, data collection and refinement parameters are listed in Table S1 (see ESI†).

Both unsymmetrical $\alpha$-diimine nickel complexes 2 (Fig. 1) and 3 (Fig. 2) bearing ortho-dibenzhydryl moiety exhibited similar geometries, and a distorted tetrahedron geometry was observed for the Ni center. However, complex 5 (Fig. 3) bearing ortho-sec-phenethyl groups exhibited symmetrical chiral pocket about the $\mathrm{Ni}$ center, and exhibited near $C_{2}$-symmetry. In the solid state, the most interesting feature of ligand is the conformation of the substituents attached to N1 and N2. These groups are rotated about $180^{\circ}$ from the position they must occupy to chelate metal Ni. The rotation has been confirmed by the crystal structure of its complex. The X-ray structures of ligand $^{18}$ and complex exhibit trans and cis conformation about the central $\mathrm{C}-\mathrm{C}$ bond of the backbone, respectively. Both aryl

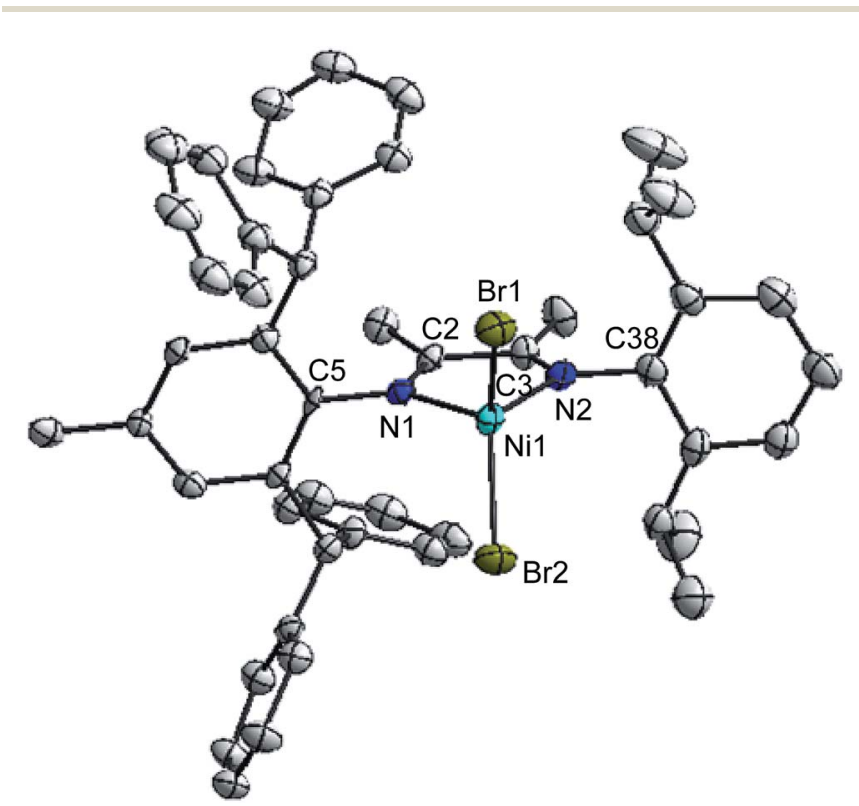

Fig. 1 Molecular structure of complex 2 with thermal ellipsoids drawn at $30 \%$ probability, and $\mathrm{H}$ atoms have been omitted for clarity. Selected bond lengths $\left(\stackrel{A}{)}\right.$ and angles $\left({ }^{\circ}\right)$ : Ni1-N1 $=2.018(13), \mathrm{Ni1}-\mathrm{N}=2.026(13)$, $\mathrm{Ni1}-\mathrm{Br} 1=2.331(3), \mathrm{Ni1}-\mathrm{Br} 2=2.334(3), \mathrm{N} 1-\mathrm{C} 2=1.27(2), \mathrm{N} 1-\mathrm{C} 5=$ 1.43(2); N1-Ni1-N2 = 80.4(5), N1-Ni1-Br1 = 114.3(4), N2-Ni1-Br1, 110.0(5), N1-Ni1-Br2 = 111.8(4), N2-Ni1-Br2 = 118.2(4), Br1-Ni1-Br2 $=116.90(13), \mathrm{C} 2-\mathrm{N} 1-\mathrm{Ni1}=111.6(11), \mathrm{C} 5-\mathrm{N} 1-\mathrm{Ni1}=128.7(10)$. 


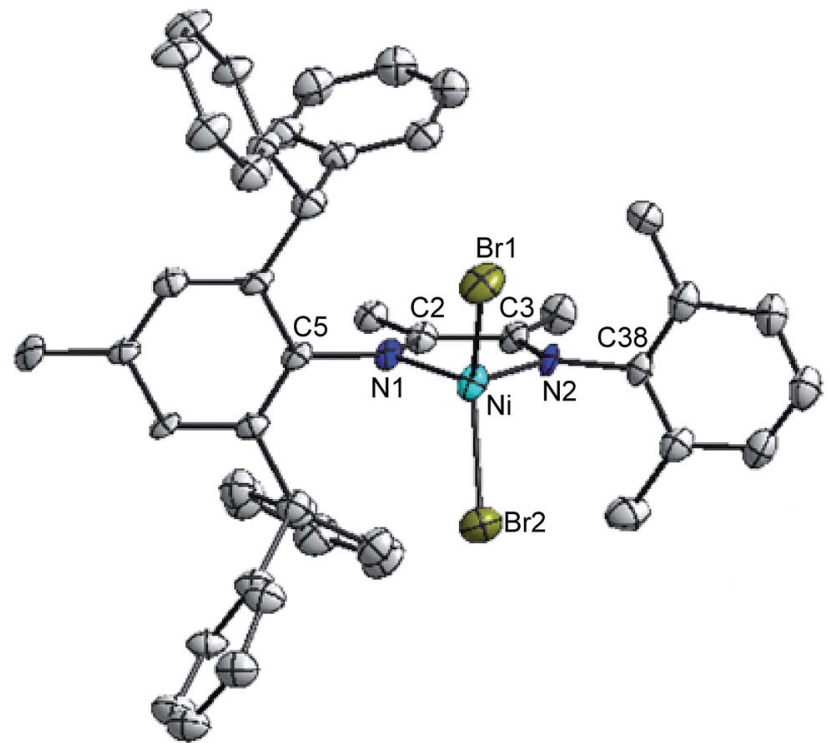

Fig. 2 Molecular structure of complex 3 with thermal ellipsoids drawn at $30 \%$ probability, and $\mathrm{H}$ atoms have been omitted for clarity. Selected bond lengths $(\AA)$ and angles $\left({ }^{\circ}\right)$ : Ni1-N1 $=2.018(13)$, Ni1-N2 = 2.026(13), Ni1-Br1 = 2.331(3), Ni1-Br2 = 2.334(3), N1-C2 = 1.27(2), $\mathrm{N} 1-\mathrm{C} 5=1.43(2), \mathrm{N} 2-\mathrm{C} 3=1.17(2), \mathrm{N} 2-\mathrm{C} 38=1.48(2), \mathrm{C} 2-\mathrm{C} 3=$ 1.53(2); $\mathrm{N} 1-\mathrm{Ni} 1-\mathrm{N} 2=80.4(5), \mathrm{N} 1-\mathrm{Ni1}-\mathrm{Br} 1=114.3(4), \mathrm{N} 2-\mathrm{Ni1}-\mathrm{Br} 1=$ 110.0(5), N1-Ni1-Br2 = 111.8(4), N2-Ni1-Br2 = 118.2(4), Br1-Ni1-Br2 $=116.90(13), \mathrm{C} 2-\mathrm{N} 1-\mathrm{C} 5=119.4(14), \mathrm{C} 2-\mathrm{N} 1-\mathrm{Ni} 1=111.6(11), \mathrm{C} 5-\mathrm{N} 1-$ $\mathrm{Ni1}=128.7(10), \mathrm{C} 3-\mathrm{N} 2-\mathrm{C} 38=121.4(16), \mathrm{C} 3-\mathrm{N} 2-\mathrm{Ni1}=115.4(13)$, $\mathrm{C} 38-\mathrm{N} 2-\mathrm{Ni1}=123.2(11)$.

rings bonded to the imine nitrogen of the $\alpha$-diimine lie nearly perpendicular to the plane formed by the nickel and coordinated nitrogen atoms. The bond angles and bond distances are consistent with those previously reported for $\alpha$-diimine nickel complexes. ${ }^{4}$ In fact, the Ni1-N1 bond distances in complex 2 $(2.026 \AA)$ and $3(2.018 \AA)$ are similar to these in $5(2.034 \AA)$, as well as the Ni1-Br1 bond distances $(2.331 \AA$ for $2 ; 2.331 \AA$ for 3 ; $2.3308 \AA$ for 5). In addition, the Br1-Ni1-Br2 angles are $116.90^{\circ}$ for complex 2 and $116.90^{\circ}$ for complex 3 are similar to these in complex $5\left(117.30^{\circ}\right)$.

\section{Ethylene polymerization studies}

All the dibromo nickel complexes 1-6 were applied to ethylene polymerization activated by $\mathrm{Et}_{2} \mathrm{AlCl}$ at the $[\mathrm{Al}] /[\mathrm{Ni}]$ molar ratio of 600 for 30 min under $9 \mathrm{~atm}$ of ethylene (Table 1). First, the influence of the polymerization temperature was studied by varying the temperature from 20 to $80^{\circ} \mathrm{C}$. The catalytic activities of complex 1 were increased with polymerization temperatures and the highest activity was observed at $80^{\circ} \mathrm{C}$ (entry 3 , Table 1 ). The maximum catalytic activities for complexes 2-5 were observed at $50{ }^{\circ} \mathrm{C}$ (entries 5, 8, 11 and 14 , Table 1), and the polymerization at $80^{\circ} \mathrm{C}$ still gave high catalytic activities on the level of $10^{6} \mathrm{~g}$ of PE per (mol Ni h) (entries 6, 9, 12 and 15, Table 1). Therefore, these $\alpha$-diimine nickel complexes 1-5 were highly active in ethylene polymerization, and showed much higher thermal stability than the corresponding methyl substituted complex 6.

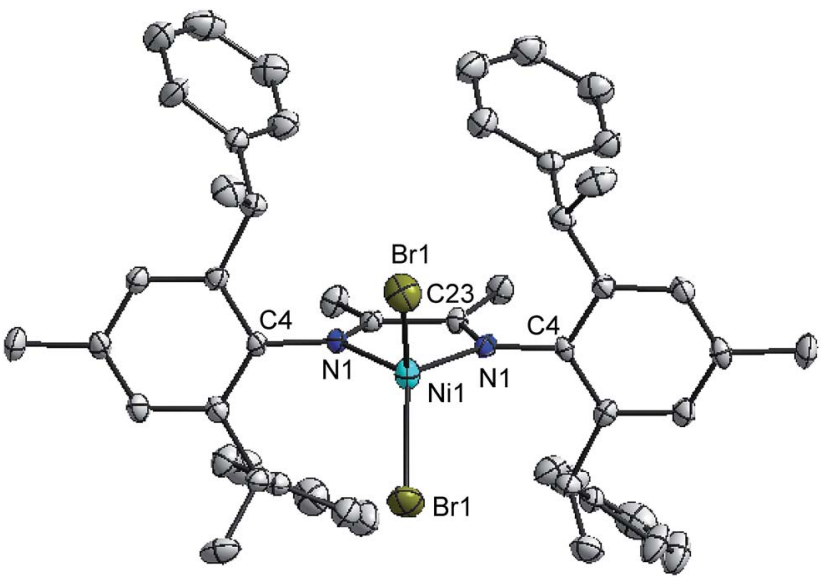

Fig. 3 Molecular structure of complex 5 with thermal ellipsoids drawn at $30 \%$ probability, and $\mathrm{H}$ atoms have been omitted for clarity. Selected bond lengths $(\AA)$ and angles $\left({ }^{\circ}\right)$ : $\mathrm{Br} 1-\mathrm{Ni1}=2.3308(12), \mathrm{Br} 1 \mathrm{i}-\mathrm{Ni1}=$ 2.3309(12), Ni1-N1 = 2.034(5), N1-C4 = 1.421(7), N1-C23=1.297(8), $\mathrm{C} 23-\mathrm{C} 23 \mathrm{i}=1.514(11) ; \mathrm{Br} 1-\mathrm{Ni1}-\mathrm{Br} 1 \mathrm{i}=117.30(9), \mathrm{N} 1 \mathrm{i}-\mathrm{Ni1}-\mathrm{N} 1=$ 81.2(3), N1i-Ni1-Br1 = 112.14(14), N1-Ni1-Br1 = 114.40(14), N1-Ni1$\mathrm{Br} 1 \mathrm{i}=112.14(14), \mathrm{N} 1 \mathrm{i}-\mathrm{Ni1}-\mathrm{Br} 1 \mathrm{i}, 114.40(14), \mathrm{C} 4-\mathrm{N} 1-\mathrm{Ni1}, 124.5(4)$.

On the other hand, the polymer molecular weight was strongly depended on the polymerization temperature with narrow molecular weight distributions of $M_{\mathrm{w}} / M_{\mathrm{n}} \leq 2.50$. The maximum molecular weight was observed at $50{ }^{\circ} \mathrm{C}$ (entries 2,5 , 8, 11 and 14, Table 1). Further increase of temperature caused a decrease in the molecular weight accompanied by broadening of the molecular weight distribution (entries 3, 6, 9, 12 and 15, Table 1). This suggests that fast chain transfer takes place at higher temperatures. ${ }^{1 a}$

Then, the effect of catalyst precursors 1-6 were investigated with $[\mathrm{Al}] /[\mathrm{Ni}]$ ratio of 600 (entries 1-18, Table 1). Complexes 1-5 produced polymers in high yields with high molecular weights $\left(M_{\mathrm{n}} \geq 1.8 \times 10^{5} \mathrm{~g} \mathrm{~mol}^{-1}\right)$ and narrow molecular weight distributions $\left(M_{\mathrm{w}} / M_{\mathrm{n}}=1.50-2.50\right)$. Steric effect of ortho-position in the anilinic moiety can be evaluated by comparing $\mathbf{1}$ to $\mathbf{4}$ and $\mathbf{5}$, 6. At $50{ }^{\circ} \mathrm{C}$ and $9 \mathrm{~atm}$ of ethylene pressure, the polymerization activity decreased in the following order, $2 \geq 3 \geq 4 \geq 5 \geq 1>6$ (entries 2, 5, 8, 11, 14 and 17, Table 1).

Complex 2 with isopropyl groups showed the highest activity among these complexes, but gave the lower molecular weight than that of complex 1 . At $50{ }^{\circ} \mathrm{C}$, the molecular weight of the polymers decreased in the following order, $1 \geq 5 \geq 2 \geq 3 \geq 4 \geq$ 6. These results indicated that the rate of chain propagation was greatly promoted by the bulky ortho-dibenzhydryl and ortho-secphenethyl substituents of the ligand's aryl rings. The highest molecular weight of the polymer obtained by complex 1 suggests that the bulky ortho-dibenzhydryl could efficiently suppress chain-transfer reactions.

The branching densities of the obtained polyethylenes were determined by ${ }^{1} \mathrm{H}$ NMR spectroscopy, ${ }^{19}$ and the results are shown in Table 1. The branching densities were increased with polymerization temperature from 20 to $80{ }^{\circ} \mathrm{C}(1,55-64 / 1000 \mathrm{C} ; 2$, 81-90/1000C; 3, 86-98/1000C; 4, 95-108/1000C; 5, 87-103/ 1000C; 6, 90-95/1000C). The branching densities were 
Table 1 Effect of catalyst and temperature on ethylene polymerization $^{a}$

\begin{tabular}{llllllll}
\hline Entry & Precat. & Temp $\left({ }^{\circ} \mathrm{C}\right)$ & Yield $(\mathrm{g})$ & Activity $^{b}$ & $M_{\mathrm{n}}{ }^{c}$ & $M_{\mathrm{w}} / M_{\mathrm{n}}{ }^{c}$ & $B^{d}$ \\
\hline 1 & $\mathbf{1}$ & 20 & 1.18 & 0.98 & 9.9 & 1.80 & 55 \\
2 & $\mathbf{1}$ & 50 & 1.69 & 1.41 & 13.1 & 1.99 & 58 \\
3 & $\mathbf{1}$ & 80 & 1.89 & 1.58 & 8.0 & 1.69 & 64 \\
4 & $\mathbf{2}$ & 20 & 2.21 & 1.84 & 7.2 & 1.62 & 81 \\
5 & $\mathbf{2}$ & 50 & 2.89 & 2.41 & 8.1 & 1.50 & 84 \\
6 & $\mathbf{2}$ & 80 & 2.59 & 2.16 & 5.2 & 2.13 & 90 \\
7 & $\mathbf{3}$ & 20 & 1.75 & 1.46 & 4.0 & 2.09 & 86 \\
8 & $\mathbf{3}$ & 50 & 2.85 & 2.38 & 6.5 & 2.06 & 91 \\
9 & $\mathbf{3}$ & 80 & 2.09 & 1.74 & 2.9 & 2.19 & 98 \\
10 & $\mathbf{4}$ & 20 & 2.11 & 1.76 & 2.2 & 1.96 & 95 \\
11 & $\mathbf{4}$ & 50 & 2.76 & 2.30 & 2.9 & 2.32 & 101 \\
12 & $\mathbf{4}$ & 80 & 1.78 & 1.48 & 1.8 & 2.50 & 108 \\
13 & $\mathbf{5}$ & 20 & 2.13 & 1.78 & 7.3 & 1.52 & 87 \\
14 & $\mathbf{5}$ & 50 & 2.65 & 2.21 & 8.7 & 1.80 & 93 \\
15 & $\mathbf{5}$ & 80 & 1.84 & 1.53 & 5.4 & 2.09 & 103 \\
16 & $\mathbf{6}$ & 20 & 0.76 & 0.63 & 0.8 & 1.67 & 90 \\
17 & $\mathbf{6}$ & 50 & 0.53 & 0.44 & 0.6 & 1.98 & 95 \\
18 & $\mathbf{6}$ & 80 & Trace & - & - & - & -
\end{tabular}

${ }^{a}$ Polymerization conditions: $\mathrm{Ni}=2.4 \mu \mathrm{mol}$ in $\mathrm{CH}_{2} \mathrm{Cl}_{2}(2 \mathrm{~mL})$; cocatalyst $\mathrm{Et}_{2} \mathrm{AlCl}, \mathrm{Al} / \mathrm{Ni}=600$; toluene $=20 \mathrm{~mL} ; 9$ atm of ethylene; time $=30 \mathrm{~min}$. ${ }^{b} 10^{6} \mathrm{~g}$ of PE $(\mathrm{mol} \text { of } \mathrm{Ni})^{-1} \mathrm{~h}^{-1} \cdot{ }^{c} M_{\mathrm{n}}$ and $M_{\mathrm{w}} / M_{\mathrm{n}}$ determined by GPC, $10^{5} \mathrm{~g} \mathrm{~mol}^{-1}$. ${ }^{d}$ Branching numbers per $1000 \mathrm{C}$ were determined by ${ }^{1} \mathrm{H}$ NMR.

decreased by increasing the steric bulkiness of the ortho substituents on the $\alpha$-diimine ligands by comparing 1 to 4 . For example, at $50{ }^{\circ} \mathrm{C}$, the number of chain branching was depended on the precatalysts and decreased in the following order, 4 [2,6-di $(H), 101 / 1000 \mathrm{C}]>3$ [2,6-di(Me $), 91 / 1000 \mathrm{C}]>2$ [2,6-di $\left({ }^{\mathrm{i}} \mathrm{Pr}\right)$, $84 / 1000 \mathrm{C}]>1$ [2,6-di $\left.\left(\mathrm{CHPh}_{2}\right), 58 / 1000 \mathrm{C}\right]$ (entries 2, 5, 8 and 11, Table 1). These results indicated that the introduction of dibenzhydryl substituent into the ortho-position of the imines ligands can decrease the branching degree of the polyethylenes. ${ }^{15,16}$ In addition, complex 5 [2,6-di(CHMePh), $50{ }^{\circ} \mathrm{C}$, $93 / 1000 \mathrm{C}]$ led to slightly lower branching density than complex 6 [2,6-di(Me), $\left.50{ }^{\circ} \mathrm{C}, 95 / 1000 \mathrm{C}\right]$.

The branching structures analysis based on ${ }^{13} \mathrm{C} N M R$ showed that 74 methyl, 7 ethyl, 5n-propyl, 4n-butyl, 1-sec-butyl (branch on branch structure) and 17 longer chains (>C4 branches) exist for the polyethylene produced by complex 4 at $80{ }^{\circ} \mathrm{C}$ (Fig. 4(i), entry 12, Table 1). In contrast, only 55 methyl branches were observed for complex 1 at $20^{\circ} \mathrm{C}$ (Fig. 4(ii), entry 1 , Table 1). The microstructure difference and the lower degree of branching density for the sterically bulkier catalysts are probably due to the relatively greater preference of insertion of ethylene into a primary metal alkyl species versus insertion into a secondary metal-alkyl species. ${ }^{16}$ The rationale for the formation of the major types of branches (methyl, ethyl, propyl, butyl and longer chains) in the polyethylenes obtained in this work is shown in Scheme 1(i).

\section{1-Hexene polymerization studies}

Chen et al. recently reported the tuning of polyethylene and poly(1-hexene) microstructures using a series of $\alpha$-diimine palladium complexes $\mathbf{C 6}$ bearing both the dibenzhydryl moiety

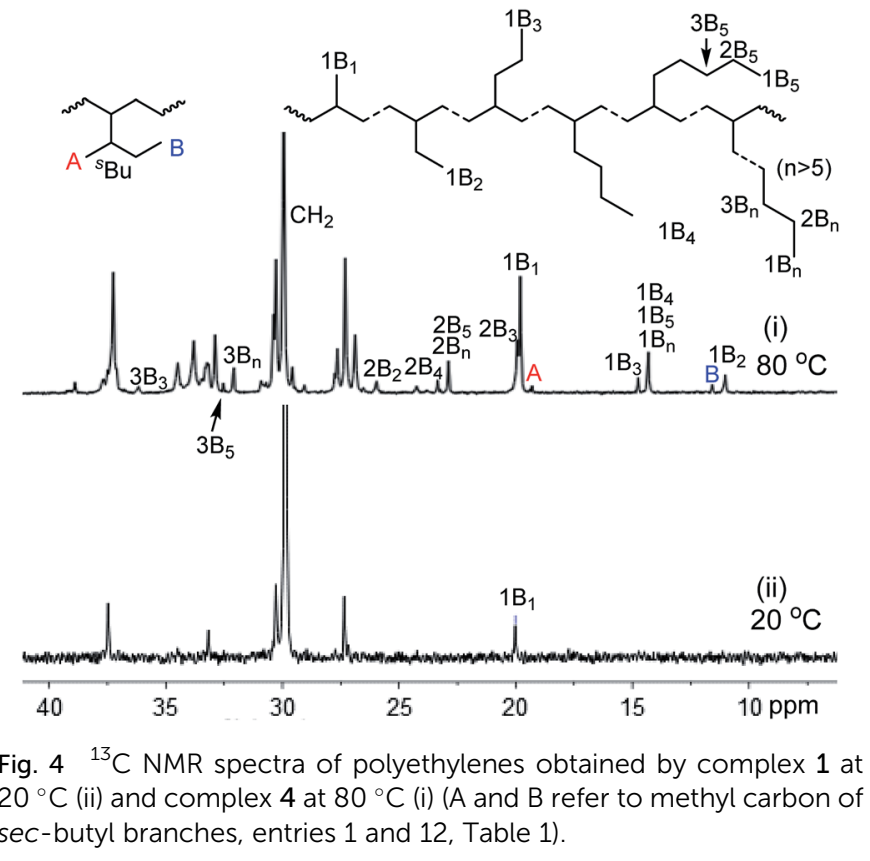

and with systematically varied ligand sterics. ${ }^{17}$ In the abovementioned ethylene polymerization, a series of $\alpha$-diimine dibenzhydryl substituted nickel complexes 1-4 with systematically varied ligand sterics showed high activities and high thermal stability, and produced polyethylene with high molecular weight. The tuning in ligand sterics enables the tuning of the polymer microstructures such as molecular weight and branching density. Therefore, polymerization of 1-hexene using these complexes 1-4 activated by $\mathrm{Et}_{2} \mathrm{AlCl}$ were carried out at various polymerization temperatures $\left(20-80{ }^{\circ} \mathrm{C}\right)$ with the $[\mathrm{Al}] /$ [Ni] ratio of 500, and the results are listed in Table 2 . In comparison with polymerization of ethylene, a decrease in catalytic activity was observed, which is due to the steric bulkiness of the 1-hexene monomer. The lowest catalytic activity was observed for 1 among these complexes, because bulky steric hindrance of complex 1 is unfavorable for 1-hexene monomer insertion, especially at lower temperature (no polymer was obtained at $20{ }^{\circ} \mathrm{C}$, entry 1 , Table 2 ).

As shown in Table 2, both the catalytic activities of complexes 1, 3 and the molecular weight of the obtained polymers were slightly increased with polymerization temperatures (entries 1-4 and 9-12), but the opposite trend was observed for complexes 2 and 4 (entries 6-8 and 13-16). Complex 2 showed the highest polymer molecular weight $\left(M_{\mathrm{n}}=3.88 \times 10^{5} \mathrm{~g}\right.$ $\mathrm{mol}^{-1}$, entry 6 , Table 2) at $40{ }^{\circ} \mathrm{C}$ among these catalysts. Complexes 2 and 3 showed good activity for 1-hexene polymerization to produce polymers with high molecular weight and narrow molecular weight distribution $\left(M_{\mathrm{w}} / M_{\mathrm{n}}=1.16-1.32\right.$, entries 6-12, Table 2), indicating the living characteristics of the polymerizations.

Generally, polymer microstructure is strongly dependent on catalyst structure and polymerization temperature. The branching structures of the poly(1-hexene)s produced by $\alpha$-diimine nickel complexes 1-4 were determined and analyzed to 
Table 2 Polymerization of 1 -hexene by $\alpha$-diimine nickel complexes $1-4^{a}$

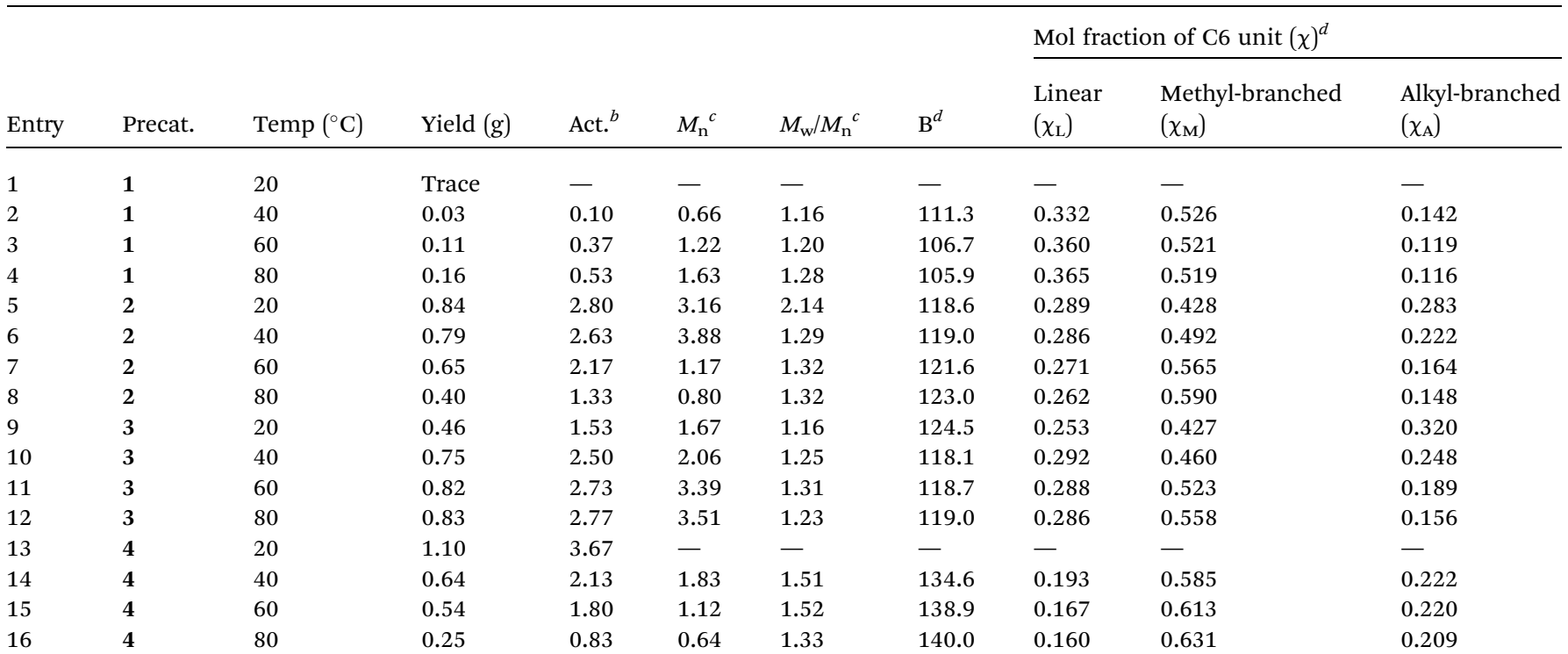

${ }^{a}$ Polymerization conditions: $\mathrm{Ni}=10 \mu \mathrm{mol}$ in $\mathrm{CH}_{2} \mathrm{Cl}_{2}(2 \mathrm{~mL})$; cocatalyst $\mathrm{Et}_{2} \mathrm{AlCl}, \mathrm{Al} / \mathrm{Ni}=500$; monomer concentration [1-hexene] $=1 \mathrm{M}$; time: $t=3 \mathrm{~h}$; solvent: toluene, total volume: $20 \mathrm{~mL} .{ }^{b}$ Activity in $10^{4} \mathrm{~g}(\mathrm{~mol} \mathrm{Ni})^{-1} \mathrm{~h}^{-1} \cdot{ }^{c} M_{\mathrm{n}}$ and $M_{\mathrm{w}} / M_{\mathrm{n}}$ determined by GPC, $10^{5} \mathrm{~g} \mathrm{~mol}{ }^{-1} .{ }^{d}$ Determined using $^{1} \mathrm{H}$ NMR spectroscopy. ${ }^{8}$

study the relationship between polymer microstructure and catalyst structure.

${ }^{1} \mathrm{H}$ NMR spectroscopy analyses have shown that the branching degree of the obtained poly(1-hexene)s are lower than the theoretical value (166.7/1000C) due to the 2,1-insertion of 1-hexene and the 1,6-enchainment (Scheme 1(iv)). The branching degree could be only tuned over a narrow range (106-140/1000C, Table 2) comparing with that in ethylene polymerization. For example, the branching densities (106-111/1000C, entries 2-4, Table 2) of the polymers obtained by complex 1 decreased with increasing temperature, but complex 4 increased slightly (135-140/1000C, entries 14-16, Table 2). However, the branching densities of the obtained polymers by complexes 2 and 3 are very close to 120 branches per 1000C, and are not depend on the polymerization temperature (entries 5-12, Table 2).

Polymers were analyzed by quantitative NMR spectroscopy to obtain the mole fractions of the three major C6 units: linear

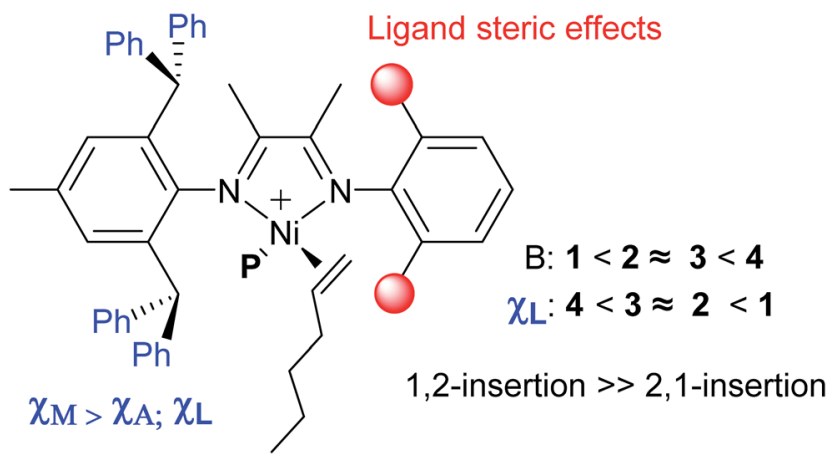

Fig. 5 Ligand steric effects of the 1-hexene insertion for $\alpha$-diimine nickel complexes 1-4.
$\left(\chi_{\mathrm{L}}\right)$, methyl-branched $\left(\chi_{\mathrm{M}}\right)$, and alkyl-branched $\left(\chi_{\mathrm{A}}\right)$ (see ESI $\dagger$ for details). ${ }^{8}$ The highly branched polymers with methyl and alkyl branches will be amorphous, while the chain-straightened $\left(\chi_{\mathrm{L}}\right)$ polymers will be semi-crystalline. As shown in the polymer microstructures by complexes $\mathbf{1}$ and 2 , the mole fractions of the three major C6 units decreased in the following order, $\chi_{M}>\chi_{L} \geq$ $\chi_{\mathrm{A}}$. The increasing steric hindrance of catalyst leads to enhanced insertion for 2,1-insertion of 1-hexene $\left(\chi_{\mathrm{L}}: 1>2 \approx 3>\right.$ 4) and the chain-walking reaction. This indicated that the steric hindrance of ortho-dibenzhydryl substituent on catalysts could suppress chain-transfer reactions (Fig. 5). The predominance of methyl branch $\left(\chi_{M}=0.43-0.63\right)$ means that the predominate 1,2-insertion followed by chain-walking forms a $2, \omega$-enchainment (Scheme 1(iii)).

In addition, the polymerization temperature also influences the branch-type distribution. The mole fraction of linear enchainment $\left(\chi_{\mathrm{L}}\right)$ of the obtained amorphous polymers (no $T_{\mathrm{m}}$ observed) by complexes 1 and 3 slightly increased from 0.33 to 0.37 and 0.25 to 0.29 with increasing temperatures, while $\chi_{\mathrm{A}}$ slightly decreased to 0.12 and 0.16 (entries $2-4$ and 9-12, Table 2). The use of the complexes 2 and 4 result in a considerable decline in $\chi_{\mathrm{L}}$ with increasing temperature (entries 5-8 and 1416 , Table 2), and the obtained polymers were amorphous.

\section{Conclusion}

In summary, polymerizations of ethylene and 1-hexene were catalyzed using a series of $\alpha$-diimine nickel complexes bearing ortho-dibenzhydryl or ortho-sec-phenethyl groups activated by $\mathrm{Et}_{2} \mathrm{AlCl}$. The ligands were modified in an attempt to change the coordination environment, steric effects and the electronic density of the metal center, eventually to modulate the activity in the polymerization of ethylene/1-hexene and to control the 
microstructure of polymers. The polymerization results indicated the possibility of precise microstructure control, depending on the catalyst structure and polymerization temperature, which in turn strongly affects the physical properties. The sterically bulky complex showed higher catalytic activities and thermal stability in ethylene polymerization and produced polyethylene with high molecular weight and much lower polyethylene branching density. The polyethylene branching densities (55-108/1000C) were decreased with increasing the bulkiness of the ligand and decreasing the polymerization temperature. However, sterically bulky complex is unfavorable for 1-hexene monomer insertion, and leads to low catalytic activity in 1-hexene polymerization.

\section{Experimental section}

\section{General considerations}

All experiments were carried out under a dry $\mathrm{N}_{2}$ atmosphere by using standard Schlenk techniques or a glovebox. Research grade ethylene was purified by passing it through an Agilent oxygen/moisture trap. ${ }^{1} \mathrm{H}$ and ${ }^{13} \mathrm{C}$ NMR spectra were recorded with a Bruker Ascend 400 spectrometer at ambient temperature unless otherwise stated. The chemical shifts of the ${ }^{1} \mathrm{H}$ and ${ }^{13} \mathrm{C}$ NMR spectra were referenced to tetramethylsilane (TMS). The molecular weight and the molecular weight distribution of the polymers were determined by gel permeation chromatography (GPC, Tosh, Tokyo, Japan) equipped with two linear Styragel columns at $40{ }^{\circ} \mathrm{C}$ using THF as a solvent and calibrated with polystyrene standards, and THF was employed as the eluent at

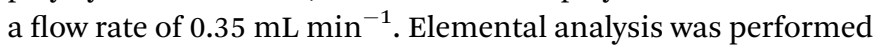
by the Analytical Center of the University of Science and Technology of China. Mass spectra were recorded on a P-SIMS-Gly from Bruker Daltonics Inc $\left(\mathrm{EI}^{+}\right)$. 1-Hexene was purchased from Kanto Chemical Co on Aldrich Chemical Company were dried over $\mathrm{CaH}_{2}$, and distilled before use. Dichloromethane, toluene, THF, and hexane were purified by solvent purification systems. $\alpha$-Diimine ligands L1-6 ${ }^{17,18}$ and complexes $1,,^{4 f, 15 a} 5,{ }^{18}$ $6^{18}$ were prepared according to reported procedures. Other chemicals were commercially obtained and purified with common procedures.

\section{Synthesis of complexes 2-4}

All complexes were prepared in a similar manner by the reaction of (DME) $\mathrm{NiBr}_{2}$ (DME = 1,2-dimethoxyethane) with the corresponding ligands in dichloromethane. A typical synthetic procedure of 2-4 is as follows: (DME) $\mathrm{NiBr}_{2}(0.31 \mathrm{~g}, 1.0 \mathrm{mmol})$ and ligand ${ }^{17}$ (1.0 mmol) were combined in a Schlenk flask under a $\mathrm{N}_{2}$ atmosphere. $\mathrm{CH}_{2} \mathrm{Cl}_{2}(20 \mathrm{~mL})$ was added, and the reaction mixture was stirred at room temperature for $12 \mathrm{~h}$. The resulting suspension was filtered. The solvent was removed under vacuum, and the resulting powder was washed with diethyl ether $(2 \times 10 \mathrm{~mL})$, and then dried under vacuum at room temperature to obtain a brown solid powder.

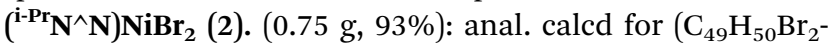
$\mathrm{N}_{2} \mathrm{Ni}$ ): C, 66.47; H, 5.69; N, 3.16. Found: C, 66.79; H, 5.60; N,
3.45. MALDI-TOF-MS (m/z): calcd for $\mathrm{C}_{49} \mathrm{H}_{50} \mathrm{BrN}_{2} \mathrm{Ni}$ : 803.2511, found: $803.1885[\mathrm{M}-\mathrm{Br}]^{+}$.

$\left({ }^{\mathbf{M e}} \mathbf{N}^{\wedge} \mathbf{N}\right) \mathbf{N i B r}_{2}$ (3). (0.71 g, 95\%): anal. calcd for $\left(\mathrm{C}_{45} \mathrm{H}_{42} \mathrm{Br}_{2}-\right.$ $\mathrm{N}_{2} \mathrm{Ni}$ ): C, 65.17; H, 5.10; N, 3.38. Found: C, 65.49; H, 5.42; N, 3.41. MALDI-TOF-MS (m/z): calcd for $\mathrm{C}_{45} \mathrm{H}_{42} \mathrm{BrN}_{2} \mathrm{Ni}$ : 747.1885, found: $747.1255[\mathrm{M}-\mathrm{Br}]^{+}$.

$\left({ }^{\mathbf{H}} \mathbf{N}^{\wedge} \mathbf{N}\right) \mathbf{N i B r}_{2}$ (4). (0.66 g, 92\%): anal. calcd for $\left(\mathrm{C}_{43} \mathrm{H}_{38} \mathrm{Br}_{2}-\right.$ $\mathrm{N}_{2} \mathrm{Ni}$ ): C, 64.45; H, 4.78; N, 3.50. Found: C, 64.49; H, 4.52; N, 3.45. MALDI-TOF-MS (m/z): calcd for $\mathrm{C}_{43} \mathrm{H}_{38} \mathrm{BrN}_{2} \mathrm{Ni}$ : 719.1572, found: $719.1244[\mathrm{M}-\mathrm{Br}]^{+}$.

\section{X-ray structure determinations}

Single crystals of complexes 2, 3 and 5 for X-ray analysis were obtained by dissolving the nickel complex in $\mathrm{CH}_{2} \mathrm{Cl}_{2}$, followed by slow layering of the resulting solution with at room temperature. Data collections were performed at 296(2) K on a Bruker SMART APEX diffractometer with a CCD area detector, using graphite monochromated MoK $\alpha$ radiation $(\lambda=0.71073$ $\AA$ ). The determination of crystal class and unit cell parameters was carried out by the SMART program package. The raw frame data were processed using SAINT and SADABS to yield the reflection data file. The structures were solved by using the SHELXTL program. Refinement was performed on $F^{2}$ anisotropically for all non-hydrogen atoms by the full-matrix leastsquares method. The hydrogen atoms were placed at the calculated positions and were included in the structure calculation without further refinement of the parameters. Details of the crystal data and structure refinements for complex 2 are listed in Table S1.†

\section{Procedure for ethylene polymerization}

In a typical experiment, a $350 \mathrm{~mL}$ glass thick-walled pressure vessel was charged with required amount of $\mathrm{AlEt}_{2} \mathrm{Cl}, 20 \mathrm{~mL}$ toluene and a magnetic stir bar in the glovebox. The pressure vessel was connected to a high pressure polymerization line and the solution was degassed. The vessel was warmed to the desired temperature using an oil bath and allowed to equilibrate for $5 \mathrm{~min}$. Then $2.4 \mu \mathrm{mol}$ of nickel complex in $2 \mathrm{~mL}$ $\mathrm{CH}_{2} \mathrm{Cl}_{2}$ was injected into the vessel via syringe. With rapid stirring, the reactor was pressurized and maintained at $9.0 \mathrm{~atm}$ of ethylene. After the desired amount of polymerization time, the vessel was vented and terminated in acidified methanol ( $m e t h a n o l / H C l=50 / 1)$. The polymers obtained were adequately washed with methanol and dried under vacuum at $50{ }^{\circ} \mathrm{C}$ for $24 \mathrm{~h}$. Analysis of the polyethylene branching by ${ }^{1} \mathrm{H}$ NMR spectroscopy: branching density, branches $/ 1000 \mathrm{C}=\left(\mathrm{CH}_{3} / 3\right) /[(\mathrm{CH}+$ $\mathrm{CH}_{2}+\mathrm{CH}_{3}$ )/2] $\times 1000 . \mathrm{CH}_{3}$ (alkyl methyl, alk- $\mathrm{CH}_{3}, \mathrm{~m}, 0.70-0.95$ ppm), $\mathrm{CH}_{2}$ and $\mathrm{CH}$ (alk-CH and alk- $\mathrm{CH}_{2}, \mathrm{~m}, \mathrm{ca}$. 1.00-1.45 ppm) refer to the intensities of the methyl, methylene and methine resonances in ${ }^{1} \mathrm{H}$ NMR spectra. ${ }^{19}$

\section{Procedure for 1-hexene polymerization}

In a typical procedure, a round-bottom Schlenk flask with stirring bar was heated $1 \mathrm{~h}$ at $150{ }^{\circ} \mathrm{C}$ under vacuum and cooled to room temperature. After drying the reactor under $\mathrm{N}_{2}$ atmosphere, toluene was added to the reactor. 1-Hexene was added 
to the toluene kept at polymerization temperature via a syringe. Then the co-catalyst $\mathrm{AlEt}_{2} \mathrm{Cl}$ was added to the toluene and the mixture was stirred for $10 \mathrm{~min}$. Polymerization was started by the addition of the catalyst solution $\left(10 \mu \mathrm{mol}, 2 \mathrm{~mL} \mathrm{CH}_{2} \mathrm{Cl}_{2}\right)$ into the reactor via syringe, and the total volume of the solution was kept at $20 \mathrm{~mL}$. After the desired amount of time, the polymerization was terminated by adding $50 \mathrm{~mL}$ of the acidified methanol (methanol $/ \mathrm{HCl}=50 / 1)$. The polymers obtained were adequately washed with methanol and dried in vacuum at $40{ }^{\circ} \mathrm{C}$ to a constant weight. Poly(1-hexene)s show long methylene sequences [linear $\left(\chi_{\mathrm{L}}\right)$ ], methyl branch $\left(\chi_{\mathrm{M}}\right)$ and alkyl branches [i.e., butyl and longer than hexyl branches $\left.\left(\chi_{\mathrm{A}}\right)\right] .^{4 e, 17}$ Analysis of the poly(1-hexene) branching by ${ }^{1} \mathrm{H}$ NMR spectroscopy: ${ }^{8}$ branching density, branches $/ 1000 \mathrm{C}=\left(\mathrm{CH}_{3} / 3\right) /\left[\left(\mathrm{CH}+\mathrm{CH}_{2}+\right.\right.$ $\left.\left.\mathrm{CH}_{3}\right) / 2\right] \times 1000 . \mathrm{CH}_{3}\left(\right.$ alk- $\mathrm{CH}_{3}\left(\chi_{\mathrm{M}}\right), \mathrm{d}, 0.70-0.87$ ppm; alkyl methyl $\left.\left(\chi_{\mathrm{A}}\right), \mathrm{t}, 0.87-0.95 \mathrm{ppm}\right), \mathrm{CH}_{2}$ and $\mathrm{CH}$ (alk-CH and alk$\mathrm{CH}_{2}$, m, ca. 1.0-1.45 ppm) refer to the intensities of the methyl, methylene and methine resonances in ${ }^{1} \mathrm{H}$ NMR spectra. 2,1Insertion was calculated by the following equation: 2,1 -Ins. $\%=$ $\chi_{\mathrm{L}}=2,1$-insertion $=(166.7-\mathrm{B}) / 166.7,{ }^{11 b, 12} \mathrm{~B}=$ branches per 1000C; $\chi_{\mathrm{M}}+\chi_{\mathrm{A}}=1-\chi_{\mathrm{L}}$.

\section{Conflicts of interest}

There are no conflicts to declare.

\section{Acknowledgements}

This work was supported by National Natural Science Foundation of China (NSFC, 21704094), the Chinese Postdoctoral Science Foundation (2017M612076), Advanced Catalysis and Green Manufacturing Collaborative Innovation Center (ACGM2016-06-01) and Yixing Taodu Ying Cai Program.

\section{Notes and references}

1 (a) S. D. Ittel, L. K. Johnson and M. Brookhart, Chem. Rev., 2000, 100, 1169-1203; (b) T. R. Younkin, E. F. Connor, J. I. Henderson, S. K. Friedrich, R. H. Grubbs and D. A. Bansleben, Science, 2000, 287, 460-462; (c) J. M. Rose, F. Deplace, N. A. Lynd, Z. Wang, A. Hotta, E. B. Lobkovsky, E. J. Kramer and G. W. Coates, Macromolecules, 2008, 41, 9548-9555; (d) C. Chen, S. Luo and R. F. Jordan, J. Am. Chem. Soc., 2008, 130, 12892-12893; (e) C. Chen, S. Luo and R. F. Jordan, J. Am. Chem. Soc., 2010, 132, 5273-5284; (f) D. Zhang and C. L. Chen, Angew. Chem., Int. Ed., 2017, 56, 14672-14676.

2 (a) R. Nakano and K. Nozaki, J. Am. Chem. Soc., 2015, 137, 10934-10937; (b) X. L. Sui, S. Y. Dai and C. L. Chen, ACS Catal., 2015, 5, 5932-5937; (c) M. Chen, W. P. Zou, Z. G. Cai and C. L. Chen, Polym. Chem., 2015, 6, 26692676; (d) Y. Ota, S. Ito, M. Kobayashi, S. Kitade, K. Sakata, T. Tayano and K. Nozaki, Angew. Chem., Int. Ed., 2016, 55, 7505-7509; (e) Z. Jian, L. Falivene, G. Boffa, S. Ortega Sánchez, L. Caporaso, A. Grassi and S. Mecking, Angew. Chem., Int. Ed., 2016, 55, 14378-14595; $(f)$ B. P. Yang, S. Y. Xiong and C. L. Chen, Polym. Chem., 2017, 8, 6272-
6276; $(g)$ T. Liang and C. L. Chen, Organometallics, 2017, 36, 2338-2344; $(h)$ Y. N. Na, D. Zhang and C. L. Chen, Polym. Chem., 2017, 8, 2405-2409.

3 (a) J. C. Yuan, F. Z. Wang, W. B. Xu, T. J. Mei, J. Li, B. N. Yuan, F. Y. Song and Z. Jia, Organometallics, 2013, 32, 3960-3968; (b) L. Zhu, Z. S. Fu, H. J. Pan, W. Feng, C. L. Chen and Z. Q. Fan, Dalton Trans., 2014, 43, 2900-2906; (c) W. P. Zou and C. L. Chen, Organometallics, 2016, 35, 1794-1801; (d) R. K. Wang, M. H. Zhao and C. L. Chen, Polym. Chem., 2016, 7, 3933-3938; (e) S. Yuan, E. Yue, C. Wen and W. H. Sun, $R S C$ Adv., 2016, 6, 7431-7438; $(f)$ P. Huo, J. Li, W. Liu, G. Mei and X. H. He, RSC Adv., 2017, 7, 5185851863; $(g)$ Y. N. Na, X. Wang, K. Lian, Y. Zhu, W. Li, Y. Luo and C. L. Chen, ChemCatChem, 2017, 9, 1062-1066; $(h)$ M. H. Zhao and C. L. Chen, ACS Catal., 2017, 7, 7490-7494. 4 (a) J. C. Yuan, F. Z. Wang, B. N. Yuan, Z. Jia, F. Y. Song and J. Li, J. Mol. Catal. A: Chem., 2013, 370, 132-139; (b) F. Z. Wang, R. Tanaka, Q. S. Li, J. C. Yuan, Y. Nakayama and T. Shiono, J. Mol. Catal. A: Chem., 2015, 398, 231-240; (c) L. H. Guo and C. L. Chen, Sci. China: Chem., 2015, 58, 1663-1673; (d) B. K. Long, J. M. Eagan, M. Mulzer and G. W. Coates, Angew. Chem., Int. Ed., 2016, 55, 7222-7226; (e) F. Z. Wang, R. Tanaka, Z. G. Cai, Y. Nakayama and T. Shiono, Polymers, 2016, 8, 160; $(f)$ L. H. Guo, S. Y. Dai and C. L. Chen, Polymers, 2016, 8, 37; $(g)$ L. H. Guo, W. Liu and C. L. Chen, Mater. Chem. Front., 2017, 1, 2487-2494.

5 (a) G. Chen, X. S. Ma and Z. Guan, J. Am. Chem. Soc., 2003, 125, 6697-6704; (b) B. K. Bahuleyan, G. W. Son, D. W. Park, C. S. Ha and I. Kim, J. Polym. Sci., Part A: Polym. Chem., 2008, 46, 1066-1082; (c) C. Chen and R. F. Jordan, J. Am. Chem. Soc., 2010, 132, 10254-10255; (d) R. K. Wang, X. L. Sui, W. M. Pang and C. L. Chen, ChemCatChem, 2016, 8, 434-440; (e) M. Li, X. B. Wang, Y. Luo and C. L. Chen, Angew. Chem., Int. Ed., 2017, 129, 11762-11767.

6 (a) E. Yue, L. Zhang, Q. Xing, X. P. Cao, X. Hao, C. Redshaw and W. H. Sun, Dalton Trans., 2014, 43, 423-431; (b) Y. Ota, S. Ito, J. Kuroda, Y. Okumura and K. Nozaki, J. Am. Chem. Soc., 2014, 136, 11898-11901; (c) Z. B. Jian, B. C. Moritz and S. Mecking, J. Am. Chem. Soc., 2015, 137, 2836-2839; (d) L. H. Guo, S. Y. Dai, X. L. Sui and C. L. Chen, ACS Catal., 2016, 6, 428-441; (e) X. H. Hu, S. Y. Dai and C. L. Chen, Dalton Trans., 2016, 45, 1496-1503; $(f)$ K. Lian, Y. Zhu, W. Li, S. Y. Dai and C. L. Chen, Macromolecules, 2017, 50, 6074-6080.

7 (a) Y. Chen, L. Wang, H. Yu, Y. Zhao, R. Sun, G. Jing, J. Huang, H. Khalid, N. M. Abbasi and M. Akram, Prog. Polym. Sci., 2015, 45, 23-43; (b) S. Y. Dai, X. L. Sui and C. L. Chen, Chem. Commun., 2016, 52, 9113-9116; (c) X. L. Sui, C. W. Hong, W. M. Pang and C. L. Chen, Mater. Chem. Front., 2017, 1, 967; (d) M. Chen and C. L. Chen, ACS Catal., 2017, 7, 1308-1312.

8 (a) T. Vaidya, K. Klimovica, A. M. LaPointe, I. Keresztes, E. B. Lobkovsky, O. Daugulis and G. W. Coates, J. Am. Chem. Soc., 2014, 136, 7213-7216; (b) F. Z. Wang, S. S. Tian, R. P. Li, W. M. Li and C. L. Chen, Chin. J. Polym. Sci., 2018, 36, 1-6; (c) C. Y. Rong, F. Z. Wang, W. M. Li and M. Chen, Organometallics, 2017, 36, 4458-4464. 
9 (a) L. H. Guo, H. Gao, Q. Guan, H. Hu, J. Deng, J. Liu, F. Liu and Q. Wu, Organometallics, 2012, 31, 6054-6062; (b) Q. Mahmood, Y. N. Zeng, X. X. Wang, Y. Sun and W. H. Sun, J. Organomet. Chem., 2015, 798, 401-407; (c) Q. Mahmood, Y. N. Zeng, X. X. Wang, Y. Sun and W. H. Sun, Dalton Trans., 2017, 46, 6934-6947.

10 (a) S. Kong, K. Song, T. Liang, C. Y. Guo, W. H. Sun and C. Redshaw, Dalton Trans., 2013, 42, 9176-9187; (b) C. J. Stephenson, J. P. McInnis, C. Chen, M. P. Weberski, A. Motta, M. Delferro and T. J. Marks, ACS Catal., 2014, 4, 999-1003; (c) H. Hu, H. Gao, D. Chen, G. Li, Y. Tan, G. Liang, F. Zhu and Q. Wu, ACS Catal., 2015, 5, 122-128; (d) F. Z. Wang, R. Tanaka, Z. G. Cai, Y. Nakayama and T. Shiono, Macromol. Rapid Commun., 2016, 37, 1375-1381; (e) F. Z. Wang, R. Tanaka, Z. G. Cai, Y. Nakayama and T. Shiono, Polymer, 2017, 127, 88-100.

11 (a) F. S. Liu, H. Y. Gao, Z. L. Hu, H. B. Hu, F. M. Zhu and Q. Wu, J. Polym. Sci., Part A: Polym. Chem., 2012, 50, 38593866; (b) J. Liu, D. R. Chen, H. Wu, Z. F. Xiao, H. Y. Gao, F. M. Zhu and Q. Wu, Macromolecules, 2014, 47, 3325-3331. 12 D. F. Zhang, E. T. Nadres, M. Brookhart and O. Daugulis, Organometallics, 2013, 32, 5136-5143.
13 (a) A. E. Cherian, J. M. Rose, E. B. Lobkovsky and G. W. Coates, J. Am. Chem. Soc., 2005, 127, 13770-13771; (b) J. M. Rose, A. E. Cherian and G. W. Coates, J. Am. Chem. Soc., 2006, 128, 4186-4187.

14 (a) D. H. Camacho and Z. Guan, Macromolecules, 2005, 38, 2544-2546; (b) D. H. Camacho, E. V. Salo, J. W. Ziller and Z. Guan, Angew. Chem., Int. Ed., 2004, 43, 1821-1825.

15 (a) J. L. Rhinehart, L. A. Brown and B. K. Long, J. Am. Chem. Soc., 2013, 135, 16316-16319; (b) J. L. Rhinehart, N. E. Mitchell and B. K. Long, ACS Catal., 2014, 4, 2501-2504.

16 (a) S. Y. Dai, X. L. Sui and C. L. Chen, Angew. Chem., Int. Ed., 2015, 54, 9948-9953; (b) S. Y. Dai and C. L. Chen, Angew. Chem., Int. Ed., 2016, 55, 13281-13285.

17 (a) S. Y. Dai, S. X. Zhou, W. Zhang and C. L. Chen, Macromolecules, 2016, 49, 8855-8862; (b) L. H. Guo, C. Zou, S. Y. Dai and C. L. Chen, Polymers, 2017, 9, 122.

18 F. Z. Wang, J. C. Yuan, F. Y. Song, J. Li, Z. Jia and B. N. Yuan, Appl. Organomet. Chem., 2013, 27, 319-327.

19 (a) J. C. Jenkins and M. Brookhart, Organometallics, 2003, 22, 250-256; (b) E. F. McCord, S. J. McLain, L. T. J. Nelson, S. D. Ittel, D. Tempel, C. M. Killian, L. K. Johnson and M. Brookhart, Macromolecules, 2007, 40, 410-420. 